\title{
Change is Good: The Past and Future of MRS
}

It is an honor and a privilege to serve as the 2009 president of the Materials Research Society. Over the course of the year, I will use this column to let you know about issues of interest to the field of materials research in general and to the Society in particular. This month, I report on some key features of the state of MRS and the priorities of the Society as I see them.

MRS is an amazingly dynamic and adaptive organization-by design. MRS was formed in 1973 to provide an alternative to materials societies that were tied to particular classes of materials or to particular industries. MRS was formed specifically to promote interdisciplinary materials research, and due care was taken in establishing the values that still drive MRS today: an unrelenting focus on technical excellence and the egalitarianism and promotion of diverse perspectives that prevent intellectual ossification.

The MRS Fall and Spring Meetings exemplify these values and their success. Each of these meetings is created "from scratch" by a new group of Meeting Chairs and Symposium Organizers who are given wide latitude to represent the cutting edge of materials research from their perspectives. These meetings have been phenomenally successful. Another great success is the MRS Bulletin, the content of which is generated each year by a new group of Volume Organizers who work to summarize the state of the art in selected fields of materials research. It is fair to say that the community (including industry and federal funding agencies) looks to MRS meetings and the MRS Bulletin to find the latest and greatest in materials research.

Of course, these MRS products are not generated by the volunteers alone. The first full-time employee of the Society was John B. Ballance, hired in 1983 as executive director. Over the years, John developed a headquarters staff to implement the unique MRS vision. Today that staff numbers nearly 40 and, as any volunteer who has worked on an MRS project knows, is supremely competent. For this, we have John to thank. However, after 25 years of

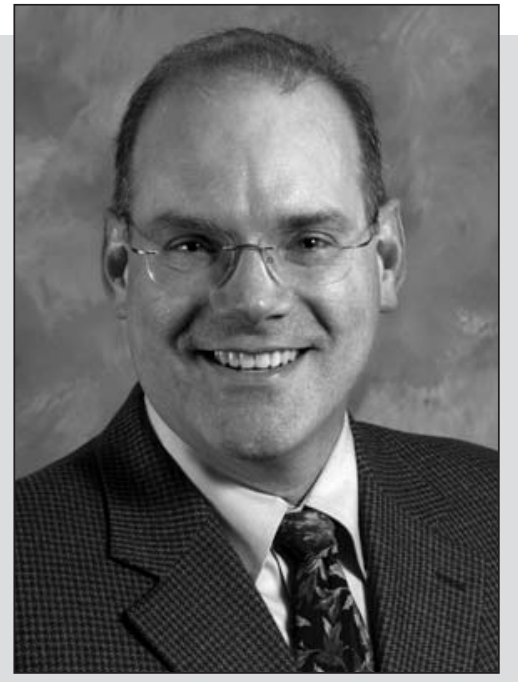

"It is the beginning of a new era.

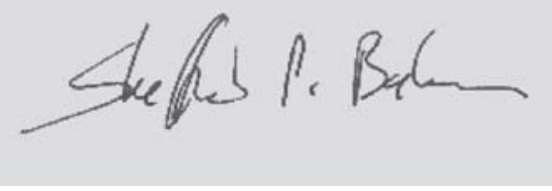

leadership and dedication, John retired in Fall 2008. His achievements and contributions to the Society were resoundingly honored at the 2008 MRS Fall Meeting in Boston. This is definitely the end of an era.

Naturally, it is the beginning of a new era as well. After an intense and very detailed search in which over 300 initial possibilities were eventually reduced to one, the MRS Board hired Todd M. Osman as the new executive director of the Materials Research Society. Todd is an active materials researcher and is therefore "one of us." He holds a PhD degree in Materials Science and Engineering from Case Western Reserve University and has actively published technical papers right up to today. In addition, he has worked in industry, government laboratories, and non-profit organizations and is a consummate stu- dent of leadership. I am delighted to be able to work with him, and I think that you will be, too.

On this note, I want to single out two people for special thanks: The first is Gordon E. Pike who was the chair of the Executive Director Search Committee. Through his efforts, this search was extraordinarily thorough and well thought-out. MRS members can rest assured that the available talent pool was comprehensively probed. In the end, the Search Committee had the difficult but pleasant task of choosing among superlatives. Much to his credit, Todd was the unanimous choice. The Society owes Gordon a debt of gratitude for this happy union.

The second person I would like to recognize is 2008 President Cynthia A. Volkert. The process of changing executive directors in a hard-charging organization like MRS is something like changing the engine in a race car in the middle of the racewithout ever leaving the track or stopping the car. It involves a lot of planning and preparation. Cynthia generated and maintained a "transition plan" that enabled the organization to function at a high level right through this major surgery. This is a terrific legacy for an MRS President, and is one that will be providing benefits for the Society far into the future. The Society owes Cynthia a debt of gratitude for her steady guiding hand.

But enough about the past. What of the future? Cynthia and Todd published an overview of MRS plans to make significant impacts in the October 2008 issue of the MRS Bulletin. We will continue to make progress in all of these areas, and more! These efforts will help facilitate the MRS mission to "advance interdisciplinary materials research to improve the quality of life."

It is an exciting time for the MRS. We are a large society based on a key set of values that allow us to continue to adapt and grow in response to changing societal and technological needs. I am glad to be a part of it, and I hope you are too.

SHEFFORD P. BAKER 2009 MRS President

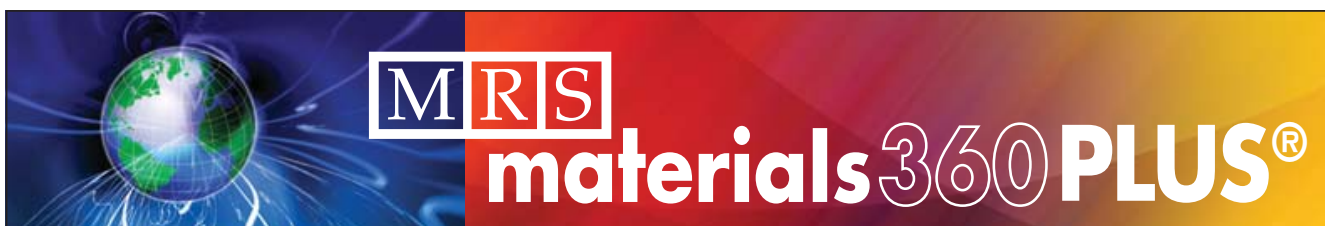

www.mrs.org/360plus
Materials News Materials Information Resources and Links Meetings Calendar and Much More! 